\title{
Diagnostic and Prognostic Analysis of Oil and Gas Pipeline with allowable Corrosion Rate in Niger Delta Area, Nigeria
}

\author{
OBASEKI, $M$ \\ Department of Mechanical Engineering, Faculty of Engineering, University of Port Harcourt, Port Harcourt, Nigeria \\ Corresponding author: obasekimartins@gmail.com
}

\begin{abstract}
This paper presents diagnostic and prognostic analysis of oil and gas pipeline industries with allowable corrosion rate using artificial neural networks approach. The results revealed sand deposit, carbon dioxide $\left(\mathrm{CO}_{2}\right)$ partial pressure, pipe age, diameter and length, temperature, flow velocity of the fluid, fluid pressure, chloride contents and $\mathrm{pH}$ value of its environment as the relevant parameters affecting corrosion of oil and gas pipeline in this region. Condition prediction of steel pipes used for the transmission of oil and gas varies $0.02 \mathrm{~mm} / \mathrm{yr}$ to $0.10 \mathrm{~mm} / \mathrm{yr}$. The training of the neural network was performed using Levenberg-Marquardt algorithm and optimal regression coefficient was equal to 0.99, for the network 10-40-1. Also, the results show a remarkable agreement with the field measurement. A corrosion severity level of two $(0.01 \mathrm{~mm} / \mathrm{yr}$ to $0.10 \mathrm{~mm} / \mathrm{yr})$ oil and gas pipelines was established from the analysis.
\end{abstract}

\section{DOI: https://dx.doi.org/10.4314/jasem.v23i5.24}

Copyright: Copyright $(92019$ Obaseki. This is an open access article distributed under the Creative Commons Attribution License (CCL), which permits unrestricted use, distribution, and reproduction in any medium, provided the original work is properly cited.

Dates: Received: 30 April 2019; Revised: 19 May 2019; Accepted 23 May 2019

Keywords: Artificial neural network, Levenberg-Marquardt algorithm, condition prediction, oil and gas data

Crude oil and natural gas are versatile feedstock due to their applications in more diverse range of sectors than other energy sources, and this gas constitutes the cleanest burning fossil fuel. (Berdzenadze, 2015). The intermediate and end user's applications of these two hydrocarbons includes production of gasoline, heating oil, diesel fuel, jet fuel, propane, asphalt and petrochemical feed stocks for manufacturing industries as well as domestic and commercial heating and electric generation (Roberge, 2008; Tawancy et al., 2013). Crude oil (petroleum) is usually extracted and associated with natural gas as a mixture of other impurities such as sulfur, nitrogen, oxygen, heavy metals and salt producing water (Roberge, 2008; Lusk et al., 2008). This mixture exists as a liquid with suspended solids in its underground geologic formations and remains liquid when brought to the well surface (Schweitzer, 2009). Hence, the mixture is separated at the well site for easy transportation of the petroleum and the crude gas to their various processing plants/refineries. A times the separated gas is flared as a waste; especially when its temporal storage and transportation facilities are limited or not available. Natural gas is sourced as non-associated gas from dry gas wells, wet gas from condensate wells and coal bed methane from coal seams (Woldeyohannes and Majid, 2011). Although pipelines, trucks, tankers and barges constitute the major means of transporting processed petroleum and natural gas products, pipelines is the safest and most economical, irrespective of the terrains and distance involved (Achebe et al,. 2012; Tawancy et al., 2013). In addition, pipeline is the only means of conveying crude oil and gas from the hole to the wellhead during the extraction and to the gathering/separation point at the well site. Pipelines used in oil and gas sector can be made of metallic alloys or plastics but carbon steel pipes remains the best means of transporting oil and gas due to its favourable thermo-mechanical properties. However, apart from design/structural, limitations and mechanical damages that are avoidable, carbon steel pipes used in oil and gas sector are prone to corrosion, which is apparently impossible to prevent due to prevailing aqueous environment of this sector. Corrosion is a destructive attack on metals by chemical, electrochemical or microbial reaction with its environment, which impairs structural integrity or load carrying capacity of the structure made from them (Revie, and Uhlig, 2008; Rajput, 2010a) . Hence, Nyborg, (2009) labeled corrosion as a natural potential hazard associated with oil and gas production and transportation facilities. Unexpected pipe failure resulting to accident, waste of products, environmental pollution, and high maintenance/production cost due to down time constitutes direct effect of oil and gas pipeline corrosion. Thus, various means of appraisal and prediction of corrosion mechanisms/rate in oil and gas pipeline such as inspection, monitoring and computer modeling techniques are highly valued even though 
forensic evaluations/mitigation method (coatingpainting and cathodic protection) remains an integral part of combating this menace. Although inspections and monitoring using high-resolution magnetic flux, sensors or ultrasonic tools can provide valuable information regarding past and present exposure conditions, both methods can neither predict the remaining life of the pipe nor provide in-depth evaluation of mechanisms of corrosion growth directly except computer models/simulations (Rajput, 2010a; Hallen et al., 2002; Mohitpour et al., 2007; Giulia et al., 2014). However, unexpected pipe failure and high maintenance cost resulting from replacement of pipes that are not due for replacement still persists in this energy sector especially in Nigeria even though the oil and gas companies in this country uses computer simulation in the analyzing and management of pipeline corrosion. This is because the modified DeWaard based simulation used by most Nigerian oil and gas companies that were developed did not account for all relevant variables influencing corrosion of oil and gas pipeline in this country. DeWaard and Milliams, (1975), modeled rate of oil and gas pipeline corrosion as a function of temperature and $\mathrm{CO}_{2}$ partial pressure that was later improved to accounts for flow velocity and diameter of pipe by DeWaard and Lotz, (1995). Nevertheless, the works of Nesic et al. (2005); Norsok, (2005); Netto et al. (2005); Keeper, (2014); Iyasele and Ntunde, (2016) indicated pipe age and length, sand flow, fluid pressure, density and viscosity, environmental $\mathrm{pH}$ value and chloride content the relevant parameters in oil and gas pipeline corrosion. Hence, the perpetual waste of products and environmental degradation as well as accident/loss life due to unexpected/sudden oil and gas pipeline failure in this country. It is therefore of economic sense that this study re-examines the significant of these factors in the initiation and development oil and gas pipeline corrosion process using artificial neural network technique because (Bassam et al., 2009) revealed that this technique provides the best/tightest model fit for this type of complex nonlinear system process than regression methods.

\section{MATERIALS AND METHODS}

Process raw field data of forty oil and gas transmission pipelines used by six oil and gas companies for offshore applications at different oil and gas fields located in Niger Delta region of Nigeria were sampled in this investigation. The oil and gas pipes selected are those whose companies' documentation tallies with their experimental data and statistical analysis revealed insignificant data outliers. The process and process predictor variable of the transmission pipes investigated include pipeline composition characteristic and fluid density, viscosity, pipe age, diameter and length, temperature, $\mathrm{CO}_{2}$ partial pressure, flow velocity of the fluid and sand flow deposit, fluid pressure, environmental $\mathrm{pH}$ and chloride content while corrosion rate constitutes the response. The companies' records as per each pipeline selected were verified with experimental corrosion measurement of the pipes' parameters using magnetic flux leakage (MFL) inspection, remotely operated Vehicle (ROV), high-resolution magnetic flux, ultrasonic thickness measurement and routine well inspection/monitoring techniques.

The data collected were divided into two different sets of twenty and twenty pipes for the development and confirmation of artificial neural network model as well as also for its multiphase interactions analysis used for the prediction of corrosion rate. The data were first normalized/scaled between -1 and 1 , transformed logarithmically using Eqn. (1) and tested for significance and variance in order to remove outliers using cook's distance/principal component analysis before applying them for the artificial neural network modeling.

$$
T_{D}=\log \left(R_{D}+0.00001\right)
$$

Where $T_{D}$ and $R_{D}$ constitutes transformed and raw data respectively and 0.00001 accounts for errors that may occur when reversing the output to actual corrosion rate in $\mathrm{mm} /$ year by taking the antilog of the neural network function. Cook's distance was computed from the relation given by Khamis, (2005) as;

$$
D_{c(i)}=\frac{\sum_{j}^{n}\left(\hat{x}_{j}-\hat{x}_{i}\right)^{2}}{M S E}
$$

Where, $D_{c(i)}$ is the Cook distance, $n$ is the number of coefficients in the regression model, $\hat{x}_{j}$ is the jth fitted response value, $\hat{x}_{i}$ is the jth fitted response value minus $i$ th observation and MSE is the mean square error. An outlier is a datum whose cook's distance is three times more than the mean cook's distance of the data set.

The neural network model used for the empirical evaluation of factors affecting corrosion of oil and gas transmission pipes was developed and analyzed using MATLAB2014b. The neural network architecture design (Fig. 1) which involves 51 layers of neurons with ten inputs, one hidden and one-output layers, applies number of neurons, $\mathrm{n} \times 10$ matrix weight, $\mathrm{W}$ of the input parameters, $\mathrm{I}_{\mathrm{p}}$ with $\mathrm{n} \times 1$ matrix of bias, $\mathrm{b}$ in determining the output corrosion rate using Eqn. (3). This network architecture was designed to use feed forward and back propagation training algorithms 
(Fig. 2) for generating and comparing predictions with given/target actual corrosion measurement by backtracking and adjusting the weights until the highest possible correlation between the input and the target data were obtained before fitting an optimal ANN function for oil and gas pipeline corrosion rate .

$$
\mathrm{CR}=f\left(W I_{p}+b\right)
$$

The transfer or activation function $f$ was determined and confirmed using Levenberg Marquardt (LM) and Bayesian Regularization (BR) algorithms respectively. In addition to correlation coefficient $(\mathrm{R})$, root mean square error (RMSE), mean absolute error (MAE) and scatter index (SI) were also applied in the testing of prediction adequacy of the fitted neural network model (Eqn. 4-7) before its experimental confirmation and multiphase interactions analysis of the level of contribution of its predictors to the response.

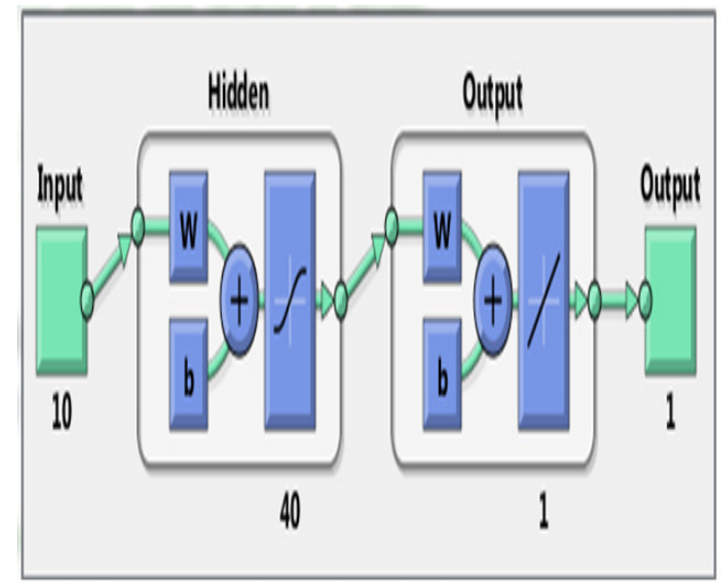

Fig 1: Developed function fitting neural network architecture of oil and gas pipeline

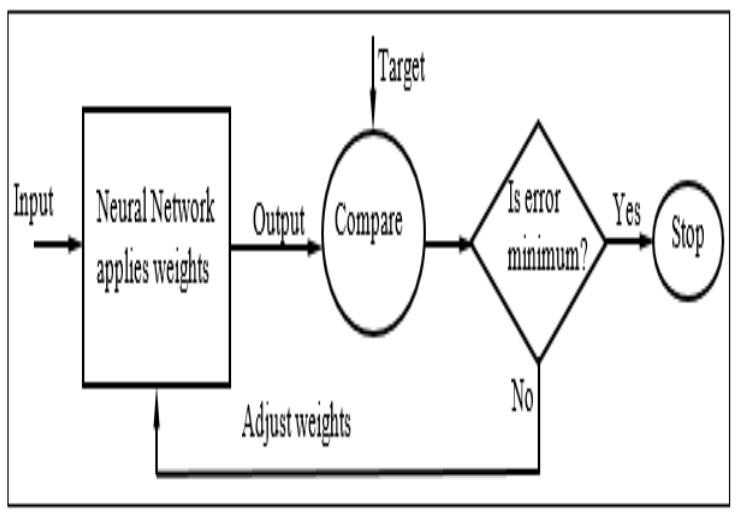

Fig. 2: Training the neural network flow chart of oil and gas pipeline rate of corrosion

$$
R=\frac{\sum_{i=1}^{N}\left(a_{i}-\bar{a}\right)\left(p_{i}-\bar{p}\right)}{\sqrt{\sum_{i=1}^{N}\left(a_{i}-\bar{a}\right)^{2} \sum_{i=1}^{N}\left(p_{i}-\bar{p}\right)^{2}}}
$$

$$
\begin{aligned}
& R M S E=\sqrt{\frac{\sum_{i=1}^{N}\left(a_{i}-p_{i}\right)^{2}}{N}} \\
& M A E=\frac{\sum_{i=1}^{N}\left|a_{i}-p_{i}\right|}{N} \\
& S I=\frac{R M S E}{\bar{p}}
\end{aligned}
$$

Where $\mathrm{a}_{\mathrm{i}}, \overline{\mathrm{a}}, \mathrm{p}_{\mathrm{i}}, \overline{\mathrm{p}}_{\mathrm{i}}$ and $N$ constitute actual corrosion rate of ith pipe, mean actual corrosion rate, predicted corrosion rate of ith pipe, mean predicted corrosion rate and number of pipes.

\section{RESULTS AND DISCUSSION}

The raw measured datasets of pipes sampled for the development and confirmation of the artificial neural network (ANN) model used for the multiphase interactions analysis of factors affecting corrosion of the pipes are shown in Table 1 and Table 2 respectively. Residual diagnostic analysis of the above measured data sets revealed that the transformed data were much flatter than the raw data (Fig. 3) and less than $0.1 \%$ outliers per $10 \times 40$ data points in each set (Fig. 4) while principal component analysis (Fig. 5) shows over $95 \%$ viability of the data in each set. Since the measured data are viable and outliers (less than $5 \%$ ) in each set are insignificant, the data sets are adequate for prediction and analysis of corrosion rate of oil and gas transmission pipes.

The optimal function fitting neural network architecture developed from this data set is shown in Fig. 1 while Eqn. 8 constitutes the model generated from it for prediction and interactions analysis of corrosion of steel pipes used for oil and gas transmission. Statistically analysis of this neural network model using Levenberg Marquardt (LM) and Bayesian Regularization (BR) algorithms (Fig. 6), regression and training (Fig. 7) plots revealed 0.99903 by training the artificial neural network, which indicates a very good coincidence with the actual results. In addition to the regression coefficient, a diagram of best validation performance is obtained, which is shown in figure 8 . The figure shows that the best validation performance is for iteration 4 and it is 0.028287; the training continued for 3 more iterations before the training stopped. The errors representing the difference between targets and outputs are obtained after training the neural network, and they are given in figure 8. In addition, its error histogram (Fig. 8) portrays the requisite dumb-bell shape indicating that errors associated with this model are evenly distributed. The error histogram shows that there is a slightest deviation between the predicted and actual values and it is 0.00065 . 
Table 1: Field data used for developing ANN function of oil and gas transmission pipes

\begin{tabular}{|c|c|c|c|c|c|c|c|c|c|c|}
\hline Pip eline & $\begin{array}{l}\text { Pipe } \\
\text { length } \\
(\mathrm{mm})\end{array}$ & $\begin{array}{l}\text { D iameter } \\
(\mathrm{mm})\end{array}$ & $\begin{array}{l}\text { Pipe } \\
\text { age } \\
\text { (year) }\end{array}$ & $\begin{array}{l}\text { Fluid } \\
\text { temp } \\
\text { ("C) }\end{array}$ & $\begin{array}{c}\text { Pressure } \\
\text { (bar) }\end{array}$ & $\begin{array}{l}\text { Velocity } \\
(\mathrm{m} / \mathrm{s})\end{array}$ & $\begin{array}{l}\mathrm{CO}_{2} \text { partial } \\
\text { pressure } \\
\text { (bar) }\end{array}$ & & $\begin{array}{l}\text { chloride } \\
\text { (mg/Kg) }\end{array}$ & $\begin{array}{l}\text { Sand } \\
\text { flow } \\
(\mathrm{m} / \mathrm{s})\end{array}$ \\
\hline 1 & 600 & 610 & 18 & 56 & 55 & 1.04 & 3.2 & 6.5 & 35.6 & 0.63 \\
\hline 2 & 400 & 600 & 14 & 69 & 60 & 1.68 & 4.9 & 5.34 & 35.9 & 1.02 \\
\hline 3 & 145 & 609.4 & 16 & 67 & 67 & 2.32 & 5.1 & 5.6 & 36.8 & 1.02 \\
\hline 4 & 145 & 406.4 & 22 & 70 & 65 & 2.85 & 2 & 5.23 & 37.9 & 1.78 \\
\hline 5 & 60 & 406.4 & 27 & 46 & 53 & 1.9 & 2.5 & 5.12 & 34.9 & 1.4 \\
\hline 6 & 121 & 609.6 & 36 & 68 & 70 & 1.28 & 3.4 & 5.24 & 33.6 & 1.95 \\
\hline 7 & 215 & 304.8 & 10 & 70 & 54 & 2.95 & 2.31 & 6.2 & 36.9 & 1.35 \\
\hline 8 & 215 & 304.8 & 12 & 56 & 46 & 1.82 & 2.6 & 3.5 & 33.3 & 1.56 \\
\hline 9 & 60 & 508 & 40 & 55 & 60 & 1.92 & 2 & 5.34 & 35.9 & 1.08 \\
\hline 10 & 1000 & 225 & 11 & 70 & 43 & 3.28 & 5.48 & 3.54 & 38.9 & 1.98 \\
\hline 11 & 45 & 508 & 39 & 69 & 54 & 2.24 & 5.2 & 4.1 & 36.8 & 1.22 \\
\hline 12 & 45 & 508 & 40 & 30 & 56 & 3.5 & 4.2 & 3.5 & 37.7 & 1.07 \\
\hline 13 & 100 & 508 & 23 & 34 & 70 & 1.92 & 3.5 & 6.45 & 31.6 & 1.23 \\
\hline 14 & 100 & 508 & 26 & 28 & 43 & 3.38 & 6 & 3.4 & 34.9 & 1.93 \\
\hline 15 & 500 & 192.7 & 9 & 70 & 59 & 3.4 & 5.1 & 4.43 & 38.5 & 1.91 \\
\hline 16 & 242 & 406.4 & 21 & 45 & 68 & 2.8 & 2.5 & 5.5 & 35.12 & 1.77 \\
\hline 17 & 242 & 406.4 & 24 & 43 & 67 & 2.58 & 3.4 & 5.65 & 32.76 & 1.45 \\
\hline 18 & 242 & 406.4 & 26 & 38 & 69.5 & 2.34 & 3.7 & 5.64 & 33.6 & 1.24 \\
\hline 19 & 242 & 406.4 & 28 & 46 & 49 & 1.84 & 6 & 4.34 & 32.9 & 1.05 \\
\hline 20 & 300 & 400 & 11 & 69 & 53 & 1.96 & 5.3 & 5.34 & 34.8 & 0.98 \\
\hline
\end{tabular}

Table 2: Field data used for confirmation of the developed ANN model of the pipes

\begin{tabular}{|c|c|c|c|c|c|c|c|c|c|c|}
\hline Pip eline & $\begin{array}{l}\text { Pipe } \\
\text { L ength } \\
\text { (mm) }\end{array}$ & $\begin{array}{l}\text { Diameter } \\
(\mathrm{mm})\end{array}$ & $\begin{array}{l}\text { Pipe Age } \\
\text { (year) }\end{array}$ & $\begin{array}{l}\text { Fluid } \\
\text { T emp } \\
\left({ }^{\circ} \mathrm{C}\right)\end{array}$ & $\begin{array}{l}\text { Pressu } \\
\text { re } \\
\text { (bar) }\end{array}$ & $\begin{array}{l}\text { Velocity } \\
(\mathrm{m} / \mathrm{s})\end{array}$ & $\begin{array}{l}\mathrm{CO}_{2} \text { Partial } \\
\text { Pressure } \\
\text { (bar) }\end{array}$ & $\mathrm{pH}$ & $\begin{array}{l}\text { Chloride } \\
\left(\mathrm{mg} / \mathrm{K}_{\mathrm{g}}\right)\end{array}$ & $\begin{array}{l}\text { sand flow } \\
(\mathrm{m} / \mathrm{s})\end{array}$ \\
\hline $\begin{array}{l}1 \\
2\end{array}$ & $\begin{array}{l}300 \\
300\end{array}$ & $\begin{array}{l}400 \\
400\end{array}$ & $\begin{array}{l}13 \\
15\end{array}$ & $\begin{array}{l}67 \\
70\end{array}$ & $\begin{array}{l}54 \\
56\end{array}$ & $\begin{array}{l}2.48 \\
2.08\end{array}$ & $\begin{array}{l}2.4 \\
3.2\end{array}$ & $\begin{array}{l}6.33 \\
6.43\end{array}$ & $\begin{array}{l}35.5 \\
33.8\end{array}$ & $\begin{array}{l}1.99 \\
1.43\end{array}$ \\
\hline 3 & 300 & 400 & 17 & 45 & 48 & 2.024 & 2.3 & 6.5 & 32.9 & 1.78 \\
\hline 4 & 300 & 400 & 19 & 65 & 47 & 3.02 & 2.56 & 5.34 & 34.2 & 1.98 \\
\hline 5 & 600 & 610 & 23 & 46 & 58 & 1.8 & 3.7 & 5.31 & 36.4 & 1.41 \\
\hline 6 & 600 & 610 & 25 & 45 & 70 & 1.24 & 5.1 & 5.11 & 36.43 & 0.76 \\
\hline 7 & 600 & 610 & 27 & 54 & 64 & 2.14 & 2.6 & 6.5 & 32.12 & 1.32 \\
\hline 8 & 600 & 610 & 29 & 45 & 67 & 1.28 & 2.55 & 5.34 & 33.76 & 0.84 \\
\hline 9 & 600 & 610 & 31 & 57 & 69 & 1.98 & 3.2 & 5.74 & 34.6 & 1.05 \\
\hline 10 & 45 & 508 & 11 & 67 & 70 & 1.52 & 3.21 & 5.34 & 35.3 & 1.04 \\
\hline 11 & 45 & 355.6 & 12 & 56 & 35 & 2.54 & 3.56 & 5.4 & 36.8 & 1.914 \\
\hline 12 & 55 & 508 & 11 & 70 & 57.4 & 2.16 & 5.67 & 5.2 & 31.2 & 1.754 \\
\hline 13 & 55 & 711.2 & 8 & 68 & 67.5 & 0.98 & 5.78 & 5.19 & 36.2 & 0.45 \\
\hline 14 & 211 & 650 & 7 & 58 & 54 & 2.24 & 4.2 & 5.64 & 34.6 & 1.54 \\
\hline 15 & 211 & 200 & 14 & 67 & 51 & 3.42 & 2.4 & 5.71 & 35.5 & 1.43 \\
\hline 16 & 211 & 400 & 17 & 69 & 49 & 2.55 & 2.6 & 5.7 & 34.12 & 1.39 \\
\hline 17 & 45 & 400 & 8 & 70 & 65 & 2.36 & 5.76 & 3.9 & 35.9 & 1.01 \\
\hline 18 & 60 & 350 & 6 & 65 & 65 & 2.46 & 2.12 & 5.3 & 37.6 & 1.55 \\
\hline 19 & 60 & 700 & 12 & 67.9 & 68 & 0.93 & 2.6 & 5.23 & 34.7 & 0.47 \\
\hline 20 & 100 & 600 & 7 & 45 & 70 & 1.18 & 5.67 & 5.2 & 33.9 & 0.59 \\
\hline
\end{tabular}

In addition, the confirmatory test plot (Fig. 9) which compared the developed ANN model prediction and the actual corrosion rate of second set of twenty pipelines (Table 2) shows that the model fitted this response (corrosion rate) adequately with over $99 \%$ accuracy which is above the acceptable 95\% prediction capability. It is also apparent from this figure that the developed ANN model predictions and the actual corrosion rates are greater than the predictions of some modified/ tradional-based simulation used by most Nigerian oil and gas companies. Thus, the inadequate prediction of oil and gas pipeline corrosion rate resulting to incessant unexpected pipeline failure in Nigerian energy sector.
The localized corrosion effect of multiphase flow interaction of both parameters with other factors is obvious in contour and surface plots (Fig. 10) of their effect on pipeline corrosion rate. The yellow-pink redregions of plots indicate the ascending severity order of the localized attack on the pipes due multiphase flow interaction of the factors. Thus, effects of sand flow deposit and pipe diameter on oil and gas pipeline corrosion cannot be set aside because this observation is in agreement with (Keeper, 2014; Arasilangkumari, 2014; IIman and Kus, 2014), which revealed that localized corrosion causes unexpected pipe failure than uniform corrosion. 



Fig. 3: Raw and transformed data plots


Fig. 4: Cook's distance and case order plots of transformed data
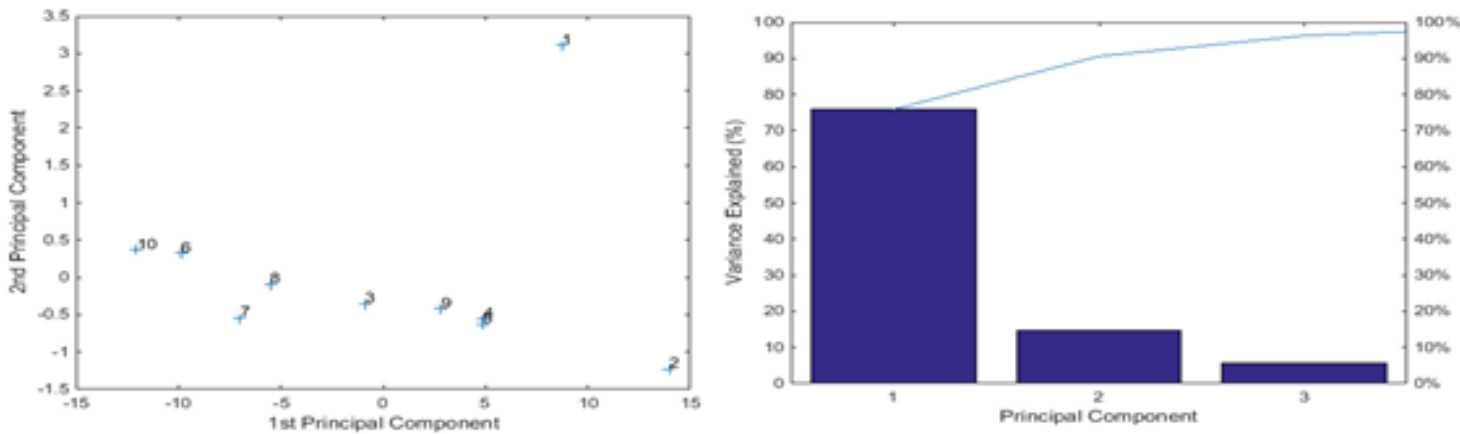

Fig. 5: Principal component analysis of the data

$$
[\text { Corrosion rate }]=\exp (f\{[\text { weights }][\text { inputs }]+[\text { bias }]\})
$$

Since this analysis confirmed that these factors are significant in the initiation and development of corrosion process in oil and gas pipeline and that the modified based simulation used by most Nigerian oil and gas companies did not account for some of these factors, it is therefore of economic and technical/safety sense that the ANN model developed is adopted for to enable effective management of corrosion in Nigerian oil and gas sector.

Severity level analysis: Prediction of corrosion rate is necessary in the oil and gas industries, as it is required when designing and installing pipes. For a pipe to be designed and install appropriate corrosion allowance has to be determined and added in the design processes. The expected corrosion rates are also required to determine the cost of maintenance and the overall cost of installation. Corrosion per year is also very important in risk determination. To reduce cost and prolong the service life of pipes, the predicted corrosion rate must be as accurate as possible so that appropriate allowances for it can be determined. This will also aid proper analysis of corrosion failure and hence appropriate design. 

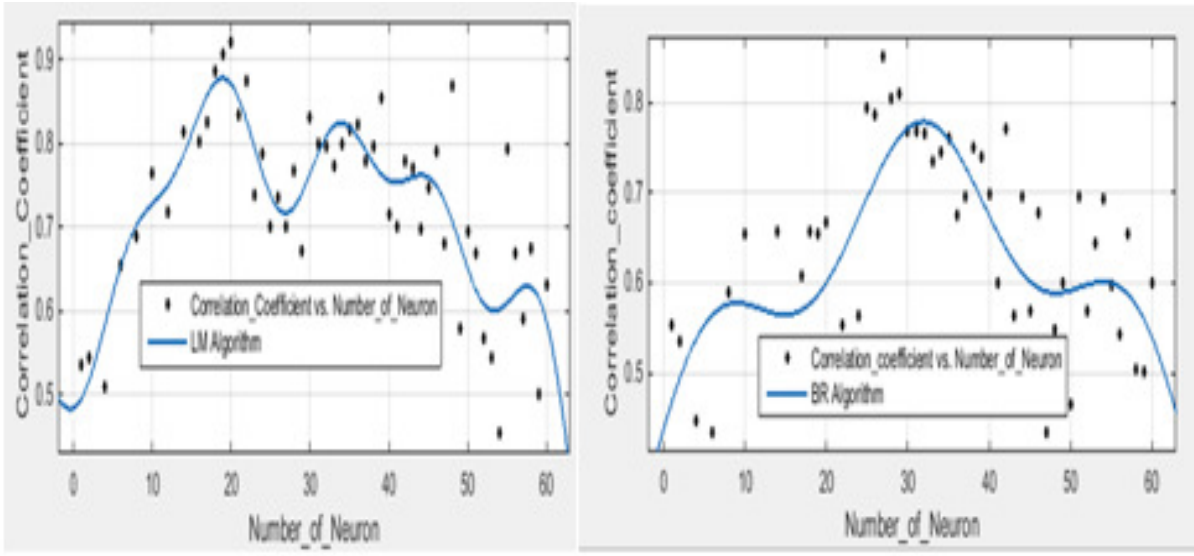

Fig. 6: Levenberg Marquardt and Bayesian Regularization algorithm for the ANN model
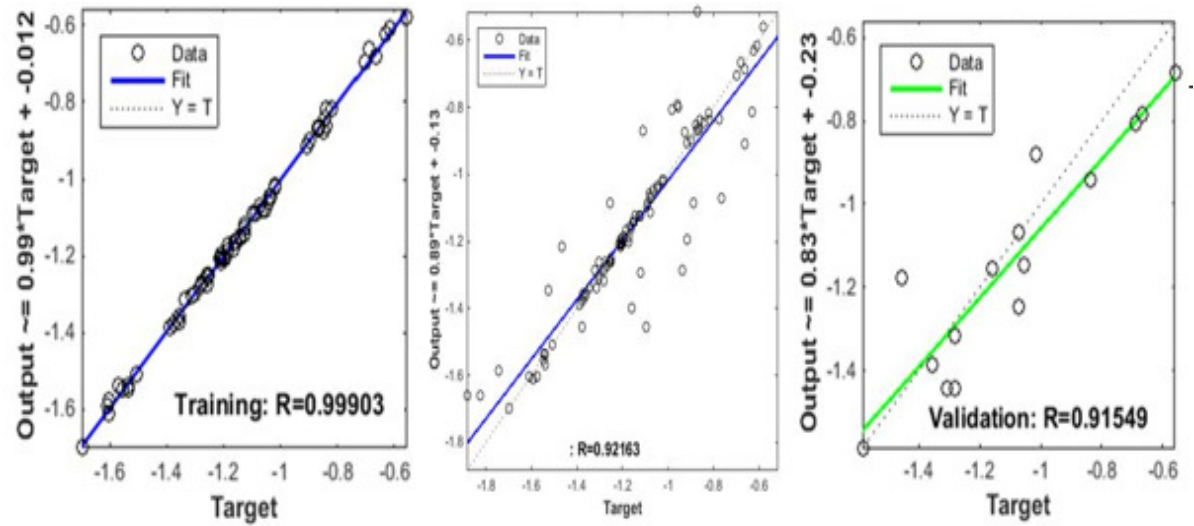

Fig. 7: Training, test and validation regression plots of the developed ANN model-predicting rate of corrosion


Fig. 8: Validation performance and Error histogram Analysis plots of the developed ANN model

The Institute of energy Technology, Norway in 2009 published industrial pipe corrosion rate prediction guidelines (Nyborg, 2009). It states that corrosion changes with the operation condition of the pipes. Conditions such as fluid properties, surrounding, and flow regime are not stagnant, and as such the input parameters for prediction of corrosion rates cannot be determined with certainty. Based on this, the institute set up Severity level for corrosion. The severity level represents the level of risk of failure of the pipe if corrosion gets to a particular magnitude. The institute places the severity level values from $1-5$, where 5 represent a very severe corrosion rate and must not be allowed in oil and gas industries. The Severity Level (Nyborg, 2009) is calculated as follows;

$$
\begin{aligned}
\text { Severity Level }= & 1 \leq[\log (\text { corrosion rate })+] \\
\leq 5(9) & \text {. }
\end{aligned}
$$

Where the corrosion rate is in $\mathrm{mm} / \mathrm{year}$. The table 3 shows the corrosion rate and the severity level. 


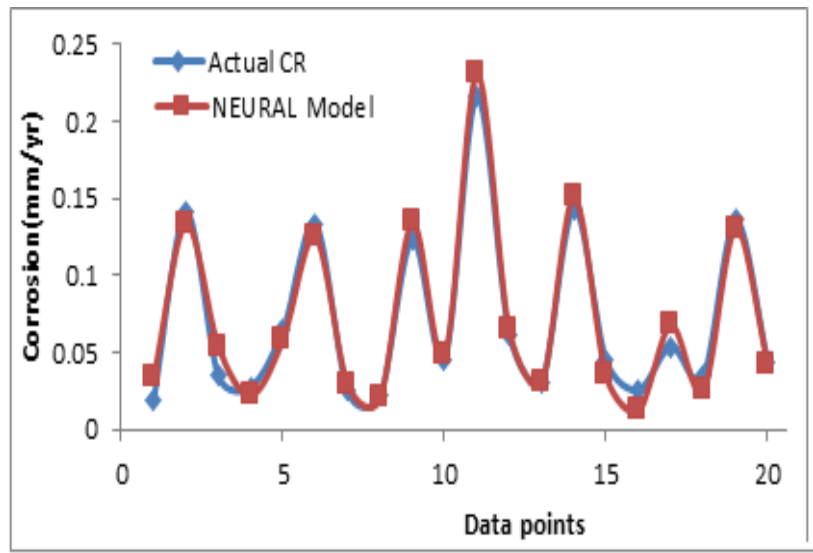

Fig. 9: Experimental confirmation of the developed ANN model
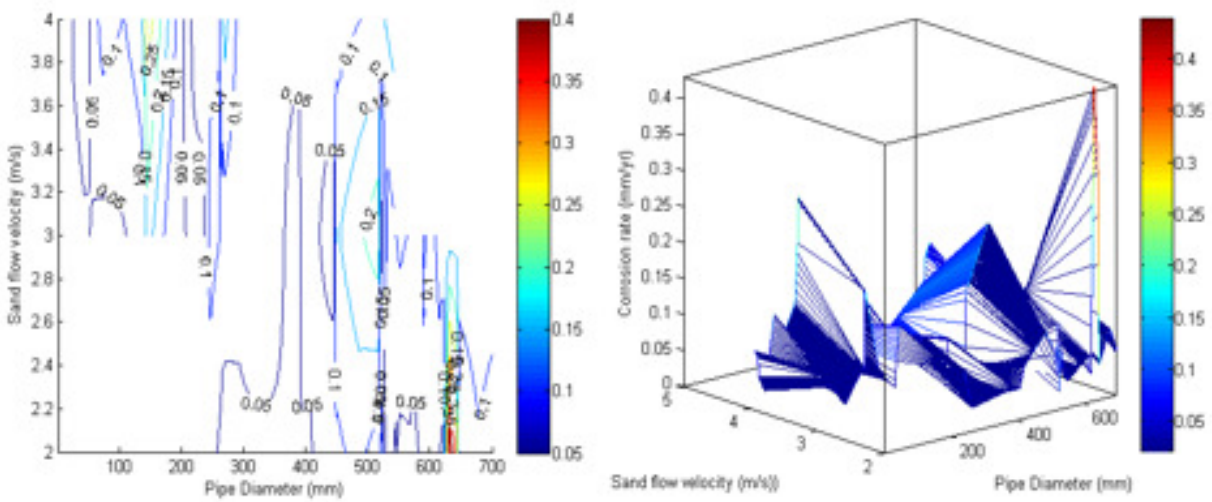

Fig. 10: Contour and surface plots of pipe diameter and sand flow interaction on oil and gas Pipeline corrosion

Table 3: Corrosion Severity Level

\begin{tabular}{ll}
\hline Corrosion Rate $(\mathbf{m m} / \mathbf{y r})$ & Severity Level \\
\hline $\mathbf{0 . 0 0}-\mathbf{0 . 0 1}$ & 1 \\
$\mathbf{0 . 0 1}-\mathbf{0 . 1 0}$ & 2 \\
$\mathbf{0 . 1 0}-\mathbf{1 . 0 0}$ & 3 \\
$\mathbf{- 1 0 . 0}$ & 4 \\
$>\mathbf{1 0 . 0}$ & 5 \\
\hline
\end{tabular}

From the table 3 it is clear that the institute states that corrosion rate above $10 \mathrm{~mm} / \mathrm{year}$ is most severe and can lead to pipe failure. However, the study shows significant understanding of the institute of energy technology that entire pipe data obtained from the Niger Delta area for this study depicts corrosion rate of $0.02-0.24 \mathrm{~mm} /$ year. This allowable limit of corrosion rate in Niger Delta corresponds to severity level of 2. Thus in Niger Delta region, corrosion rate with severity level of 2 is considered severe from the analysis. A remarkably good level of agreement was found between rate of corrosion predicted using this method and actual (field) corrosion measurements.

Conclusion: This study confirmed a ten parameters condition prediction model with the relevant parameters affecting corrosion of oil and gas pipeline in Niger Delta region of Nigeria. The results obtained training the neural network for the rate of corrosion show good coincidence with actual value (experimental). Also, the analysis shows the level of severity in the oil and gas industries with respect to the institute of energy technology standard Norway. The use of ANN model developed in this study is therefore recommended for pipeline engineers to eliminate perpetual waste of products and environmental degradation as well as loss life associated with oil and gas pipeline in the region.

\section{REFERENCE}

Achebe, CH; Member, I; Nneke, UC; Anisiji, OE (2012). Analysis of Oil Pipeline Failures in the Oil and Gas Industries in the Niger Delta Area of Nigeria: Proceedings of the International Multi Conference of Engineers and Computer Scientists (IMECS), 11:1-6. 
Arasilangkumari, N (2014). Engaging Degradation Mechanisms of Materials in a Tourney. An Investigation into the Philosophy of Material Selection as a Mitigating Measure and Strategy. Master Thesis, University of Stavanger.

Bassam, A; Toledo, DO; Hernandez, JA (2009). Artificial Neural Network for the Evaluation of $\mathrm{CO}_{2}$ Corrosion in a Pipeline steel. J. of Solid State Electrochemist. 13(5): 773-780.

Berdzenadze, I (2015). Oil's role in the World Economy and in the Global Crises. Accessed on 12/06/17 from http://ireport.cnn.com/docs/DOC1227007

DeWaard, C and Lotz, U (1995). Influence of Liquid Flow Velocity on Corrosion a Semi-Empirical Model, NACE International Corrosion Conference, Paper No 128, Orlando, FL.

DeWaard, C and Milliams, DE (1975) Carbonic Acid Corrosion of Steel. Corrosion, 31(5): 177-.181.

Giulia, DM; Roberta, V; Manuela, G; Giovanna, G (2014). A Neural Network Predictive Model of Pipeline Internal Corrosion Profile. Intern. Confr. on Systems Infm. Model. and Sim. 18-23.

Hallen, JM; Gonzalez, JL; Caleyo, F; Lagos, FF (2002). In-line Inspection Guides Integrity Assessment of Sour Gas. $O \& G$. J. 62-68.

IIman, MN and Kusmono (2014). Analysis of Internal Corrosion in Subsea oil Pipeline: Case Studies Engr. Fail. Analysis Elsevier. 2 (1): 1-8.

Iyasele, EO and Ntunde, DI(2016). Algorithm for Determining the Corrosion Rate of Oil Pipelines using Modified Norsork M-506 Model: A Case Study. Umudike J. of Engr. and Tech. (UJET), 2(2): 170-181.

KATARIA and Sons, 6, Guru Nanak Market, Nai Sarak, Delhi, 854 - 866.

Keeper, G (2014). Corrosion Modeling: Influencing Factors. A Technical Newsletter for the Oil and Gas Industries.www.gateinc.com

Khamis, A (2005). The Effects of Outliers Data on Neural Network Performance. J. of Appl. Sci. (Asian Network for Scientific Information), 5(8): 1394-1398.
Lusk, D; Gupta, M; Boinapally, K; Cao, Y (2008). Armoured Against Corrosion. Hydrocarbon Engr. 13(11): 115-118

Mohitpour, M; Golshan, H; Murray, A (2007). Pipeline Design and Construction: A Practical Approach, Third Edition. American Society of Mechanical Engineers, Three Park Avenue, N.Y. 100(16): 1-21

Nesic, S; Cai, J; Lee, KLJ (2005). A Multiphase Flow and Internal Corrosion Prediction Model for Mild Steel Pipelines. In: Proceedings of the Corrosion 2005, NACE Intern., paper no. 05556.

Netto, TA; Ferraz, US; Estefe SF (2005). The Effect of Corrosion defects on the Burst Pressure of Pipelines. J. of Constructional Steel Research, 61(1): 1185-1204.

Norsok, S (2005). Norsok standard $\mathrm{M}-506: \mathrm{CO}_{2}$ Corrosion Prediction Model. Standards Strandveien N-1326 L.N. 1-28.

Nyborg, R (2009). Guidelines for prediction of $\mathrm{CO}_{2}$ corrosion in oil and gas production systems. Institute of Energy Technology, Norway.

Rajput, R (2010a) A Textbook of Material Science and Engineering (S.I Units). S.K.

Revie, W and Uhlig, H (2008). Corrosion and Corrosion Control: An Introduction to Corrosion Science and Engineering, Fourth Edition. A John Wiley and Sons, Inc, Publication, N.J. 513-514.

Roberge, PR (2008). Corrosion Engineering Principles and Practices. Mc-Graw-Hill (Publishers) N.Y. 342-345

Schweitzer, PA (2009). Fundamentals of Corrosion: Mechanisms, Causes, and Preventative Methods. CRC Press. T. \& F. Group, Boca Raton London, N.Y. 1-23.

Tawancy, HM; Al-Hadhrami, LM; Al-Yousef, FK (2013). Analysis Corroded Elbow Section of Carbon Steel Piping System of Oil-Gas Separator Vessel. C. S. in Engr Fail. Analy. 1(1): 6-14.

Woldeyohannes, AD; Majid, MAA (2011). Effect of Age of Pipes on Performance of Natural Gas Transmission Pipeline Network System. J. of App. Sci. 11(9): 1612-1617. 